REGARDS

SUR LECONOMIE ALLEMANDE

BULLETIN ECONOMIQUE DU CIRAC

\section{Regards sur l'économie allemande}

Bulletin économique du CIRAC

$78 \mid 2006$

Varia

\title{
Communication et médias
}

ALM (ed), ALM-Jahrbuch 2005. Landesmedienanstalten und privater Rundfunk in Deutschland / HODENBERG Christina von, Konsens und Krise. Eine Geschichte der westdeutschen Medienöffentlichkeit 1945-73 / Jahrbuch Fernsehen 2006 / Medienrelevante verwandte Märkte in der rundfunkrechtlichen Konzentrationskontrolle. Auswahl, Messung und Bewertung. Dokumentation des Symposiums der Kommission zur Ermittlung der Konzentration im Medienbereich (KEK) / SCHÜTZ Walter J., Zeitungen in Deutschland. Zeitungsatlas 2004 / WOLFF Volker, ABC des Zeitungs- und Zeitschriftenjournalismus

\section{OpenEdition}

Journals

Édition électronique

URL : http://journals.openedition.org/rea/468

DOI : $10.4000 /$ rea.468

ISBN : 978-2-8218-0852-2

ISSN : 1965-0787

Éditeur

CIRAC

Édition imprimée

Date de publication : 1 octobre 2006

ISSN : 1156-8992

Référence électronique

"Communication et médias », Regards sur l'économie allemande [En ligne], 78 | octobre 2006,

document 1, mis en ligne le 05 juin 2008, consulté le 22 septembre 2020. URL : http://

journals.openedition.org/rea/468; DOI : https://doi.org/10.4000/rea.468

Ce document a été généré automatiquement le 22 septembre 2020.

(c) CIRAC 


\section{Communication et médias}

ALM (ed), ALM-Jahrbuch 2005. Landesmedienanstalten und privater Rundfunk in Deutschland / HODENBERG Christina von, Konsens und Krise. Eine Geschichte der westdeutschen Medienöffentlichkeit 1945-73 / Jahrbuch Fernsehen 2006 / Medienrelevante verwandte Märkte in der rundfunkrechtlichen Konzentrationskontrolle. Auswahl, Messung und Bewertung. Dokumentation des Symposiums der Kommission zur Ermittlung der Konzentration im Medienbereich (KEK) / SCHÜTZ Walter J., Zeitungen in Deutschland. Zeitungsatlas 2004 / WOLFF Volker, ABC des Zeitungs- und Zeitschriftenjournalismus

\section{RÉFÉRENCE}

ALM (ed), ALM-Jahrbuch 2005. Landesmedienanstalten und privater Rundfunk in Deutschland, Vistas Verlag, Berlin, 2006, 472 p. HODENBERG Christina von, Konsens und Krise. Eine Geschichte der westdeutschen Medienöffentlichkeit 1945-73, Wallstein Verlag, Göttingen, 2006, 512 p. Jahrbuch Fernsehen 2006, Adolf-Grimme-Institut, Marl, 2006, 556 p. Medienrelevante verwandte Märkte in der rundfunkrechtlichen Konzentrationskontrolle. Auswahl, Messung und Bewertung. Dokumentation des Symposiums der Kommission zur Ermittlung der Konzentration im Medienbereich (KEK), Vistas Verlag, Berlin, 2006, 400 p.

SCHÜTZ Walter J., Zeitungen in Deutschland. Zeitungsatlas 2004, Vistas Verlag, Berlin, 2006, 11 cartes WOLFF Volker, ABC des Zeitungs- und Zeitschriftenjournalismus, Coll. Praktischer Journalismus, UVK Verlagsgesellschaft, Constance, 2006, 373 p.

1 A l'heure où la numérisation de la communication génère d'importantes mutations du fonctionnement de l'espace public, l'ouvrage de HODENBERG qui retrace l'évolution du rôle des médias dans le jeu démocratique ouest-allemand de 1945 à 1973 apporte un précieux éclairage. L'un des principaux pivots du rôle d'accompagnement actif et critique de l'action politique que jouent encore aujourd'hui les médias d'information 
(voir Gabel, Lasserre dans ce numéro) aura été un changement de paradigme qui s'est effectué sous Willy Brandt. En s'entourant de journalistes réputés pour le conseiller dans son action, il a tissé des liens de partenariat entre la sphère politique et ses relais dans l'opinion - mais des liens interactifs, les médias se faisant également ce relais critique de l'opinion qu'ils sont restés depuis. Ce schéma a hautement contribué à la transparence de la démocratie (ouest-)allemande. Il était en franche rupture avec l'approche de Konrad Adenauer qui cherchait au contraire à encadrer l'information soit en pilotant les médias, soit en misant sur la connivence avec certains journalistes. Il est vrai que les priorités de l'après-guerre n'étaient pas les mêmes : les médias servaient la rééducation démocratique des Allemands.

Mais cette nécessité, renforcée par l'instrumentalisation des médias par les régimes hitlérien et soviétique, a cimenté une approche de la régulation qui, pour préserver le pluralisme des opinions, s'est longtemps concentrée exclusivement sur le partage des pouvoirs entre le monde politique (exécutif) et un ' 4 e pouvoir' indépendant des trois autres. Cette approche nourrit toujours jusqu'aux fondements du droit sectoriel de la concurrence dans une branche d'activités qui est aujourd'hui un marché où la multitude des acteurs et supports d'information garantit un haut degré de pluralisme. Or cette situation pose problème, comme le révèlent les actes d'un symposium organisé voici un an par la Commission d'évaluation de la concentration dans les médias (KEK) et comme l'a confirmé depuis l'échec du rapprochement entre les éditions Springer et le groupe ProSiebenSat.1 (voir REA 75/06), un projet qui aura été au cœur des préoccupations des autorités de régulation des médias, comme le montre leur rapport annuel conjoint (ALM Jahrbuch 2005).

3 L'histoire de la difficile relation entre sphères politique et médiatique entrave aujourd'hui la modernisation de la régulation d'un secteur qui, s'il est toujours ce «facteur éminent du processus de formation de l'opinion publique » que voit en lui le Tribunal constitutionnel fédéral, n'en est pas moins un marché dynamique et diversifié. On en jugera en consultant la dernière édition de l'Atlas des quotidiens publié à intervalles réguliers depuis 1954 par W. SCHÜTZ: on y voit combien la presse allemande est une réalité locale, présente sur l'ensemble du territoire sans disparités notables. On en jugera également en se reportant au Jahrbuch Fernsehen qui passe en revue l'activité de la télévision. Réalisé notamment par l'Institut Adolf-Grimme qui décerne tous les ans le prix du même nom attribué aux meilleures émissions TV de l'année selon des critères de qualité exigeants, il met bien sûr en relief les aspects qualitatifs de l'abondante production de fiction ou d'information. Or le Grimme-Preis, s'il est l'un des plus prestigieux, s'inscrit dans une très longue liste de prix récompensant la qualité professionnelle des produits et du travail des journalistes. La compétence se construit : si le métier s'apprend lors de la formation initiale (souvent en apprentissage), il s'entretient au quotidien - une nécessité absolue pour préserver la qualité de l'information dans un secteur en pleine mutation. L'ABC du journalisme, un manuel pratique régulièrement revu et actualisé, constitue la référence en la matière. (ib) 